\author{
RAFAel SAgRedo BAEZA*
}

\title{
1914: De Gran Guerra a tragedia de la humanidad. Algunos libros y fuentes 2014
}

\section{4-1914}

Los cien años del inicio de la llamada, en su momento, "Gran Guerra", hasta que la iniciada en 1939 vino a cambiar su nombre por el de Primera Guerra Mundial, para terminar hoy transformada por la historiografía en "tragedia europea", ha significado la aparición de numerosos y heterogéneos estudios, textos y testimonios sobre la confrontación que en el Reino Unido muestra, a lo menos, dos grandes posiciones respecto del carácter de la evocación. Una de ellas es la de quienes sostienen que la Gran Bretaña está en todo su derecho a conmemorar -incluso celebrar- su épico triunfo, en una contienda a la que fue arrastrada por Alemania; la otra posición es la de los que, previendo las consecuencias políticas que en la actualidad y el futuro tendría situar a Alemania en un papel tan incómodo, prefieren un tono menos marcado por el acento en quienes tuvieron la principal responsabilidad en desatar el conflicto, y promueven una memoria centrada en el carácter de catástrofe que tuvo la guerra para todos los involucrados, salvando así de ofender a la potencia que hoy es Alemania ${ }^{1}$. Por lo demás, es una muestra elocuente de que toda historia es historia contemporánea -en el sentido que está condicionada por el contexto en que se produce- y que son las preocupaciones del momento, de los tiempos en que se escribe, las que darán el tono, los énfasis y en definitiva los enfoques y las interpretaciones sobre los que llamamos hechos, sucesos, procesos y personajes históricos. Todos los cuales, por lo señalado, así como lo son hoy, podrían dejar de serlo mañana; o bien ser objeto de reinterpretación de acuerdo a los imperativos de época.

La mayor parte de los estudiosos -entre ellos, los comentados más adelante- se decanta por la primera de las posiciones, que creen se ajusta a lo que efectivamente ocurrió a comienzos del siglo $\mathrm{XX}^{2}$; mientras que los políticos y sus cercanos prefie-

\footnotetext{
* Académico del Instituto de Historia de la Pontificia Universidad Católica de Chile. Correo electrónico: rsagredo@uc.cl.

1 A partir de agosto de 1914 se enfrentaron en los campos de batalla -en el terreno diplomático, comercial y político venían haciéndolo desde hacía años- los Aliados, Francia, Rusia e Inglaterra, contra las llamadas potencias centrales, Alemania, Austria-Hungría y el Imperio Otomano. Por cierto hubo otros participantes, pero estos fueron los principales.

2 El que todos sean ingleses en este caso no es factor determinante de su opinión. Recordemos que fue un historiador alemán, Fritz Fischer, quien en 1961 fundó una escuela y desató la llamada "controversia Fischer", al publicar Griff nach der Weltmacht: Die Kriegszielpolitik des kaiserlichen Deutschland 1914-1918 (en inglés: Germany's Aims in the First World War), en el que atribuye a Alemania la principal y determinante responsabilidad de la Gran Guerra.
} 
ren una mirada más neutra, que haga comprensible que la guerra fue una tragedia común, como efectivamente lo fue.

Más allá de las causas y efectos de la contienda, tal vez los tópicos más llevados y traídos por los historiadores del conflicto, junto con su historia militar, son las nuevas sensibilidades históricas marcadas, por ejemplo, por la historia social, la nueva historia cultural, la de género y la de la vida cotidiana, abundan en las repercusiones que tuvo la conflagración para la población, relatando, explicando, acercándose cada vez más, entre otras cosas, a la lucha tal y como les pareció que fue a los que participaron en ella; existiendo notables monografías sobre los más diversos aspectos, en particular, relativos a las consecuencias sociales del acontecimiento. Todo, también, en medio del estímulo que recibieron los estudios de la memoria colectiva y el nacionalismo a raíz del fin de la Guerra Fría y el colapso de la Unión Soviética.

Un solo ejemplo - pero gran ejemplo- de lo que afirmamos es el libro de Virginia Nicholson, Singled out. How Two Million Women Survived Without Men after the First World War, en el que su autora explica las consecuencias para las mujeres inglesas de la extraordinaria mortandad masculina en la Primera Guerra Mundial, las que vieron reducidas drásticamente sus oportunidades de formar una familia ${ }^{3}$. Sin pareja para casarse, en una población en que las mujeres superaban a los hombres en una gran proporción, las "chicas del excedente" ya no pudieron, como entonces se esperaba que ocurriera, cumplir su destino natural: el matrimonio y la crianza de los hijos. Fue entonces que se inició la transformación acelerada de su papel en la sociedad, pues no solo tuvieron que suplir a los hombres faltantes en muchas actividades antes propias de ellos, sino que salieron de sus casas para no volver a ellas, cambiaron sus aspiraciones e ideales y se aventuraron a estudiar, trabajar, emprender negocios y muchas otras tareas que contribuyeron notablemente a mejorar sus expectativas y horizontes, y a situarlas en los diversos quehaceres que desempeñan. Con ello, de paso, transformaron al conjunto de la sociedad, dando forma al mundo contemporáneo.

El libro de Nicholson, al que podríamos sumar muchos otros, no solo muestra la originalidad y calidad de la historiografía inglesa, sino también que detrás de los grandes acontecimientos que deslumbran por los sucesos espectaculares y dramáticos que los constituyen están las sociedades, la población civil, los sujetos comunes, quienes experimentan durante décadas los efectos de una coyuntura que, corrientemente, se ha relatado y analizado a la luz de la política y como antecedente de la Segunda Guerra Mundial.

Pero como los estudios particulares son eso, monografías, es preciso aludir también a un texto de visión amplia, global, de la contienda, que permita conocer el panorama general. La obra de David Stevenson, 1914-1918, la historia de la Primera Guerra Mundial, en muchos sitios es recomendada como "el” libro sobre la Gran

3 Virginia Nicholson, Singled out. How Two Million Women Survived Without Men after the First World War, London, Penguin Books, 2007 (en español: Ellas solas. Un mundo sin hombres tras la Primera Gran Guerra Mundial, Madrid, Turner, 2008). 
Guerra, si se tuviera tiempo para leer solo uno sobre el tema ${ }^{4}$. Y a diferencia de muchos de los editados en los últimos años, que solo se concentran en lo ocurrido en 1914, se ocupa de los cuatro años que duró la conflagración. Describe las principales operaciones militares, las decisiones de los líderes de las potencias de la época, sus ambiciones y debilidades, pero también, las condiciones materiales, tecnológicas, industriales y económicas de los países participantes. Se trata de un ensayo y relato que explica el estallido de la guerra, cómo se transformó en una contienda a escala mundial, su desenlace y el legado que todavía proyecta. Una obra exhaustiva, de gran erudición y con múltiples ángulos de análisis de una guerra considerada como "un aprendizaje horrible de lo que era un conflicto moderno: un conflicto que era a la vez una pugna internacional y una lucha general", lo que nunca antes se había producido ${ }^{5}$.

Entre las conclusiones de Stevenson, la que plantea que "parece probable que sea en el terreno fronterizo entre la historia cultural y la política donde sigan encontrándose las pistas más importantes sobre los resortes principales que desencadenaron el conflicto", resulta muy estimulante por las proyecciones analíticas que supone ${ }^{6}$. Apunta a la necesidad de comprender el fenómeno desde una perspectiva de largo o mediano plazo, estructural en ocasiones, y asociada a la cultura y a las ideologías; pero también desde una perspectiva coyuntural y político-militar, en relación con los años que antecedieron a la guerra y al papel de sus protagonistas. Dos dimensiones que, junto con complementarse para efectos de ofrecer una buena historia, permiten narrar y explicar, satisfaciendo la necesidad de dar a conocer los hechos, y una obligación tratándose de hacer historia, como es la compresión y la interpretación.

\section{Y LA ESCRITURA DE LA HISTORIA}

Entre los trabajos más recientes -de hecho, aparecidos el 2013-y relevantes por sus repercusiones, por ejemplo, traducidos casi inmediatamente después de publicados, además del reconocimiento que han tenido sus autores, están los libros de Margaret MacMillan, 1914. De la paz a la guerra, y el de Max Hastings, 1914. El año de la catástrofe ${ }^{7}$.

Ambos, además, ofrecen ejemplos de las formas en que en la actualidad -y, en realidad, hace un buen tiempo ya- se entrega la producción historiográfica. El de MacMillan, catedrática de la Universidad de Oxford e historiadora profesional con

${ }^{4}$ David Stevenson, 1914-1918, la historia de la Primera Guerra Mundial, Barcelona, Debate, 2014 (publicada originalmente en inglés el 2004).

5 Ibid., 707 y 763.

6 Ibid., 760.

7 Margaret MacMillan, 1914. De la paz a la guerra, Madrid, Turner, 2013 (edición original en inglés: The War that Ended Peace. How Europe Abandoned Peace for the First World War); Max Hastings, 1914. El año de la catástrofe, Barcelona, Crítica, 2013 (edición original en inglés: Catastrophe. Europe goes to war 1914). En ambos casos los títulos originales marcan su carácter y dan una idea más fiel de su contenido. 
numerosos reconocimientos, es el clásico libro académico, en el estilo analítico y tono ponderado que se espera de una obra de esa naturaleza, incluidas sus agudas reflexiones metodológicas. El de Hastings - un destacado periodista, alguna vez corresponsal de guerra y documentalista que, a lo largo de su carrera, fue derivando hacia la historia hasta llegar a escribir numerosos libros de gran éxito editorial y reconocimiento académico- ofrece un relato más vivo y directo, menos convencional y con muchos elementos, como juicios y evaluaciones sobre quienes lo han precedido en el estudio de la Gran Guerra, adjetivaciones para los hechos y personalidades de los que se ocupa y, sobre todo, la narración de los sucesos acaecidos en los campos de batalla durante 1914 que, sin duda, cautivan al lector. Esto no impide que se tornen reiterativos para los menos entusiastas de las alternativas concretas de los combates en los campos de batalla.

El carácter de estos autores, el de su producción intelectual y, con ella, el curso tomado por los escritos históricos en las últimas décadas, se puede apreciar incluso en los temas y títulos de sus libros anteriores. Ahí están los llamativos y vibrantes de Hastings: Armagedón. La derrota de Alemania, 1944-1945; Némesis. La derrota del Japón, 1944-1945; La guerra de Churchill o Se desataron todos los infiernos; todos, presumimos, traducidos a más de un idioma. Mientras que los de MacMillan, París 1919: seis meses que cambiaron el mundo; Juegos peligrosos. Usos y abusos de la Historia; Women of the Raj: The Mothers, Wives, and Daughters of the British Empire in India; y Nixon and Mao: The Week that Changed the World, aunque más convencionales en sus temas, ya muestran en sus títulos no solo su interés por momentos culminantes del siglo XX o el papel esencial que atribuye a algunas coyunturas, sino también que, progresivamente, se fue acercando al "mercado", aprovechando su vasta experiencia como investigadora y reconocida capacidad como historiadora. Cualidades que, seguro, su editor tuvo muy presente cuando, como la propia MacMillan reconoce, le sugirió que se ocupara de la Gran Guerra cuando ella "no tenía intenciones de escribir un libro sobre su estallido", pues lo consideraba un asunto "demasiado trillado" que, sin embargo, al final la cautivó y sobre el que terminó ofreciendo un enfoque original para un tema apasionante, sobre todo cerca de su centenario ${ }^{8}$.

Muestra, a su vez, del papel de los editores académicos, para no hablar de los editores en general, tan lejano a nuestra realidad, pero fundamentales en otras latitudes a la hora de fomentar y promover por razones comerciales, obviamente, temas, obras y autores que, de este modo, salen del estrecho círculo de la academia y se transforman en fenómenos editoriales y, por lo tanto, de la cultura de masas. Realidad que no implica renunciar a la investigación, al rigor metodológico y al trabajo propio de un historiador; pero sí ser capaz de exponer, escribir y, en definitiva, conquistar a un ávido lector de historia de calidad a través de un tema de interés, una explicación original y una prosa ágil. En la actualidad, ello también implica la capacidad de satisfacer los deseos de saber, de conocer y de comprender la conducta, la vida, las actitudes y las decisiones de los sujetos como los lectores, ojalá en la dimensión más íntima y personal posible, pero mostrando los alcances que para las grandes masas

\footnotetext{
8 Las citas en MacMillan, op. cit., 762.
} 
tuvieron los hechos que se ofrecen como historia, aunque también interpretándolos y ofreciendo un sentido o significado de su ocurrencia.

\section{COMO DESAFÍO HISTORIOGRÁFICO}

Expresión de lo que señalamos se encuentra en los libros que nos ocupan, en los que, desde las primeras páginas, se advierte el propósito de explicar cómo Europa se involucró en el conflicto; pero también, en evaluar la responsabilidad que cada una de las potencias tuvo en los acontecimientos que se desataron en julio de 1914. El propósito se entiende no solo como una necesidad propia de la historiografía, sino también como reacción a la noción de que la Gran Guerra fue inevitable. Para Margaret MacMillan, "una conclusión peligrosa", sobre todo considerando "que nuestro mundo se asemeja en muchos aspectos al de los años previos a 1914" y, en particular, se enfrenta a desafíos similares "de orden revolucionario ideológico, como el auge de la violencia religiosa o de las protestas sociales", o fruto de "la tensión entre las naciones que prosperan y las que entran en decadencia, como China y Estados Unidos". Todo lo cual la lleva a advertir: "Necesitamos pensar cuidadosamente acerca de cómo se generan las guerras y cómo podemos preservar las paz", en especial, en una época en la cual "las naciones se enfrentan entre sí, tal como hicieron antes de 1914, en lo que sus líderes consideraban un juego controlado de alardes y simulaciones"

Max Hastings, aludiendo a la historiografía existente sobre el conflicto, centrada en la tormenta política y diplomática que llevó a la guerra, o bien en la historia militar de la conflagración, reconoce que él ha tratado de aunar ambas tendencias para, a lo menos, tratar de responder "la gran pregunta: ¿Qué le sucedió a Europa en 1914?”. Una tarea ardua si se considera, como afirma, que "el estallido de la guerra se ha descrito como la serie de acontecimientos más compleja de la historia" "10, mucho más difícil de comprender y explicar que la Revolución Rusa, el principio de la Segunda Guerra Mundial o la crisis de los misiles de Cuba; este último, un acontecimiento citado más de una vez en ambos libros, también en el de Stevenson, por la decisiva actuación del presidente John Kennedy al resistir la presión de los militares, actitud que no tuvieron los políticos en 1914.

El papel de las figuras de primera línea, reyes, políticos y militares, su responsabilidad a la luz de lo acontecido, es otro gran tema presente en las obras. Un asunto que, a su vez, lleva a la discusión sobre qué resulta más trascendente de atender: las acciones de los personajes o los movimientos sociales, los procesos, los contextos y las estructuras. MacMillan es categórica sobre lo primero: "La tragedia de Europa y el mundo, vista desde hoy, estuvo en que ninguno de los actores clave de 1914 fue un líder con la suficiente grandeza e imaginación, ni con el suficiente coraje, como para

\footnotetext{
9 Ibid., 25.

10 Hastings, op. cit., 18.
} 
oponerse a las presiones que empujaban a la guerra" ". La actuación de los gobernantes incluso se produce pese a que, a lo largo del siglo XIX, se había tomado conciencia de que "la guerra resultaba ineficiente y demasiado costosa para la resolución de las disputas", lo que explica el cada vez más frecuente uso del arbitraje como mecanismo de resolución de los conflictos nacionales ${ }^{12}$. Sin embargo, esto fue totalmente olvidado en 1914, entre otras razones, por la existencia de planes militares de gran magnitud y complejidad, prácticamente imposibles de alterar, que dejaron cada vez menos margen de decisión a los civiles, al punto que estos no se atrevieron a obviarlos o contenerlos. Entre otras razones, porque los desconocían y no manejaban alternativas. Por eso, MacMillan sostiene que los hombres en el poder fallaron en 1914.

A todos tal vez se les podría aplicar las palabras que Hastings cita de Lloyd George, ministro de Hacienda británico antes de la guerra, a propósito de una reunión con el canciller alemán de la época, Bethmann Hollweg, y la opinión que se formó de él en 1908: "una personalidad atractiva, pero no deslumbrante, no me ha dado la impresión de haber conocido a un hombre con poder para, tal vez, algún día, alterar el destino", cancelando así cualquier posibilidad de haber conocido a un líder ${ }^{13}$.

Muy relacionado con los sujetos y sus actos, entre los que debemos considerar sus relatos de los hechos, está el tema de las fuentes y de la forma en que las memorias deben ser apreciadas y valoradas. En las obras de MacMillan y Hastings, como en muchas otras sobre el conflicto, se suceden las referencias a ellas, mostrando, a lo menos, dos realidades. La costumbre de los líderes políticos, pero también de quienes los rodeaban y asistían en sus funciones, de registrar casi diariamente los hechos y situaciones que vivían, tanto como las impresiones que les causaban sus interlocutores. Y es que esta no fue solo una práctica de las personalidades, sino que estuvo muy extendida en un segmento de la población que también, como nuestros autores lo reflejan al citarlas, registraban los acontecimientos de los cuales fueron contemporáneos, tal vez, mostrando con ello conciencia de que en las primeras décadas del siglo XX se vivían "años de vértigo", como los llamó Philipp Blom, y que por lo tanto merecían quedar anotados ${ }^{14}$.

Como las segundas, por su espontaneidad y falta de pretensión, entre otras características, son mucho más fiables, MacMillan y Hastings nos previenen sobre las de los de los políticos, militares y demás actores participantes en la toma de decisiones.

11 MacMillan, op. cit., 25.

12 Ibid., 361. A propósito de este tema, y de nuestra investigación en curso sobre la delimitación y demarcación de la frontera chileno-argentina, una breve alusión a nuestra historia que confirma todos los planteamientos de MacMillan. El recurso del arbitraje fue el utilizado por Argentina y Chile para resolver sus controversias de límites en el cambio de siglo entre el XIX y el XX. Esta determinación mereció elogios del árbitro inglés que medió entre las partes: "El recurrir al arbitraje y no a las armas marca una nueva era en la historia de las repúblicas de Sudamérica. Este acto colocó a ambos países en una posición moral más elevada dentro de todas las naciones que la más ventajosa de las guerras. Argentina y Chile han dado una lección al resto del mundo". Los conceptos del reconocido geógrafo Thomas H. Holdich datan de 1904.

13 Hastings, op. cit., 86.

14 Citamos el texto de Philipp Blom, The Vertigo Years (London, Weidenfeld \& Nicolson, 2008), sobre la "cultura y cambio en occidente entre 1910 y 1914", como agregó a su título original la edición española que Editorial Anagrama publicó en Barcelona el 2010. 
Entre otras razones, por su evidente afán por eludir responsabilidades, acomodando los hechos y, sobre todo, su actuación en ellos a la "buena" memoria que pretendían dejar de sí mismos. De ahí el esfuerzo de los estudiosos por abarcar el mayor número de fuentes posibles y de contrastarlas entre sí. Hastings es particularmente insistente en este punto, cuando afirma que, si bien todos los historiadores por lo general se enfrentan a la escasez de fuentes, los de la Gran Guerra, por el contrario, "se ven afligidos por el fenómeno inverso: hay una sobreabundancia de material en muchas lenguas, y buena parte es sospechoso o claramente corrupto", en particular tratándose del producido por los protagonistas, cuyas memorias, afirma, “son elusivas y quizá incluso directamente falsas con respecto a lo acontecido" ${ }^{15}$.

\section{FOTOGRAFIADO Y SENTENCIADO}

Pero más allá de la necesaria ponderación que es preciso realizar de las fuentes, en realidad, la tarea de los historiadores de la Gran Guerra se ha visto facilitada, podríamos decir, por el abrumador conjunto de testimonios de primera mano existentes sobre el conflicto. En las últimas décadas y años, estos han pasado de los baúles, los áticos y los cajones familiares, a los museos, bibliotecas e instituciones que preservan el patrimonio y la memoria, pero también al papel impreso. Infinidad de publicaciones con testimonios, poemas, fotografías, ilustraciones, correspondencia, diarios, entre otros registros, de actores protagónicos y secundarios en la Gran Guerra, dan fe de lo que afirmamos. Reflejando a su vez el interés de la sociedad, de los lectores de hoy por conocer lo que le ocurrió hace un siglo a sujetos comunes como ellos. Todo aunado con la cultura de la imagen que nos es tan propia, lo que explica la gran cantidad de libros con fotografías editados a propósito del centenario del inicio de la guerra. Incluso existe uno, el de Birger Stichelbaut y Piet Chielens, The Great War seen from the Air in Flanders Fields. 1914-1918, que ofrece una perspectiva inédita de la conflagración ${ }^{16}$.

Algunos, como The Great War. A Photographic Narrative, con imágenes que dan cuenta del conjunto, de diversos escenarios y casi siempre capturadas en espacios públicos, son un elocuente registro de que en 1914 no solo se dispararon las armas, también las cámaras que comenzaban a masificarse ${ }^{17}$. Otros, como el de Peter Doyle y Chris Foster, Remembering Tommy: The British Soldier in the First World War, que entrega la dimensión íntima, personal, privada, incluso afectiva, de los soldados ingleses a través de fotos de los objetos que alguna vez utilizaron en las diversas instancias del conflicto ${ }^{18}$. Una obra en que, además, el color contribuye todavía más a acercar al lector y a otorgar actualidad a objetos comúnmente apreciados en blanco

15 Hastings, op. cit., 19 y 90.

16 Birger Stichelbaut y Piet Chielens, The Great War seen from the Air in Flanders Fields. 1914-1918, Reino Unido, Mercatorfonds, 2013.

17 The Great War. A Photographic Narrative, London, Imperial War Museum, 2013.

18 Peter Doyle y Chris Foster, Remembering Tommy: The British Soldier in the First World War, Gran Bretaña, Copyrighted Material, 2013. 
y negro y, por lo tanto, percibidos como antiguos y lejanos; pero que ahora se nos representan como ordinarios, en el sentido de cercanos, propios y comunes a personas como cualquiera, sensibilizando sobre las circunstancias en que fueron utilizados.

Entre los libros de fotografías, The Great War. 1914-18, In Flanders Fields Museum. Photographic Collection merece, a nuestro juicio, una mención particular, pues ofrece registros únicos, icónicos y hasta ahora inéditos, provenientes de colecciones individuales y privadas, obtenidas de álbumes de fotos personales donados al museo por las familias de los veteranos ${ }^{19}$; casi todas características que deberían ser valoradas por los historiadores, como lo son por el público en general. En especial si, como es el caso, entrega una perspectiva humana y cotidiana del conflicto, incluidos los horrores de que es capaz la especie, entre ellos la devastación de la naturaleza como metáfora de la catástrofe general.

La selección está centrada casi exclusivamente en la relación entre el hombre/soldado y la muerte/guerra, en el frente y sus alrededores. Todo a través de una estética pulcra, en blanco y negro, con las fotografías a página completa, la mayor parte de ellas sin margen, y que tiene como intención contribuir a moralizar. Es la guerra en toda su fealdad que, según los editores, debe afectar, impresionar, molestar incluso, también como imagen. Rechaza así toda pretensión de objetividad, muchas veces falsa por interesada, que algunos esgrimen para, la mayor parte de las ocasiones, justificar los horrores y, con ellos, muchas veces también a sí mismos, tratándose de hechos recientes.

Las fotografías exhiben crudamente los primeros planos del frente y del combate, acercando al lector a lo que el soldado/fotógrafo pudo sentir al obturar y disparar, en una dimensión muy cercana a la experiencia real que, inevitablemente, lleva a la condena de los hechos en que este se vio involucrado. Esta cercanía contrasta con el libro que ofrece la Gran Guerra a través de tomas aéreas, en el que la "lejanía" no es solo una metáfora. Pese a lo cual, por la pequeñez de los sujetos en la superficie terrestre, la futilidad de la conflagración también queda al desnudo. De modo que cualquiera sea el ángulo y escala en que se refleje, la Gran Guerra queda sentenciada ante los ojos y el juicio del lector actual.

\section{COMO HISTORIOGRAFÍA}

Estamos seguros de que fuentes como las mencionadas han sido también un poderoso estímulo para nuevas formas de hacer historia. En sí mismas, ellas no solo reflejan una opción editorial, el compromiso con valores universales, sensibilidad de época o empatía con la desgraciada suerte de las mayorías; también el afán por hacer comprensible nuestro presente a través del conocimiento del pasado, para lo cual el estilo resulta indispensable de atender.

19 The Great War. 1914-18, In Flanders Fields Museum. Photographic Collection, Ypres, Hannibal Publishing, 2013. 
Relacionado con la forma de escribir historia, uno de los méritos del libro de MacMillan es su capacidad para, en medio de sus explicaciones, ofrecer una frase inesperada, un testimonio inédito pero muy oportuno para demostrar sus asertos. Utilizando correspondencia la mayor parte de las veces, un diario privado o alguna otra fuente no pública y menos todavía oficial, pero sí de carácter íntima y espontánea, corrientemente fruto de alguno de los actores de la época, la autora sorprende al lector cada cierto tramo con su talento para, en medio de una inmensidad de fuentes consultadas, seleccionar las palabras de los contemporáneos que logran captar con mayor agudeza las situaciones y caracterizar precisamente a los personajes y sus motivaciones, cuando no sus carencias y limitaciones, muchas de la cuales explican lo ocurrido. MacMillan apoya de este modo su relato e interpretación con recursos de una efectividad implacable.

Una muestra de esto es el relato de la visita que en abril de 1904 Lloyd George hizo a un anciano estadista del partido liberal, lord Rosebery, el día que se firmó la entente entre Inglaterra y Francia: "Sus primeras palabras de saludo fueron: 'bueno, supongo que estás tan contento como los demás con este acuerdo francés'. Yo le aseguré que estaba encantado de que nuestras enmarañadas y confusas relaciones con Francia se hubieran arreglado al fin. A lo que me respondió. 'Estás completamente equivocado. ¡Significa que al final habrá guerra con Alemania!'”20.

También hay que valorar en Margaret MacMillan su capacidad para proyectar los hechos y procesos que relata, y que condujeron a la Gran Guerra, hacia el futuro de estos acontecimientos $\mathrm{y}$, por lo tanto, hasta nuestro presente, para ayudarnos a comprender el pasado. Son frecuentes sus llamados de atención sobre la similitud de situaciones de entonces con las de ahora, por ejemplo, su alusión a los estados del golfo Pérsico y a la China actual para explicar los dilemas de la Rusia de la preguerra, y su referencia a hechos que han marcado el siglo XX y el curso de los acontecimientos, como la crisis de los misiles de 1962, la visita de Richard Nixon a China en 1972 o el caso Watergate, los cuales son mencionados en relación a algún suceso de la época que explica. Algunas advertencias sobre lo azaroso que resulta el acontecer y que, por lo tanto, nada es seguro o cierto, como cuando recuerda "que antes de 1914 Alemania y Gran Bretaña habían sido sus mejores socios comerciales respectivos" ${ }^{21}$, sin duda resultan incómodas para los que profetizan y aseguran, por ejemplo, que cuanto mayor es el comercio entre las naciones, menor es la posibilidad de que lleguen a una guerra. En el libro de Stevenson, su comparación de la Gran Guerra con la intervención de los Estados Unidos en Vietnam, "por su sombría fama de horror e inutilidad", ofrece otro ejemplo de que estos autores son capaces de abordar sus temas de una manera que resulta interesante y empática para sus lectores ${ }^{22}$.

En este afán, tampoco olvidan el atractivo juego de la historia contrafactual, en el caso de MacMillan, como recurso para hacer más comprensibles sus planteamientos. Por eso pregunta muy asertivamente y a propósito de la carrera armamentista naval

\footnotetext{
20 MacMillan, op. cit., 226.

21 Ibid., 191.

22 Stevenson, op. cit., 765.
} 
de Alemania antes de la guerra: “¿Qué hubiera sucedido si una parte de los recursos dedicados a la armada se hubieran entregado al ejército? Y si se hubieran fortalecido con hombres y armas las tropas alemanas en 1914, ¿habría triunfado entonces su ataque contra Francia ese verano, como estuvo a punto de ocurrir?"23.

En otras ocasiones, la autora advierte sobre el hecho que la continuidad de algunas conductas resulta fundamental para explicar los conflictos. Como la tentación seductora, en tanto intento de aglutinar a la sociedad en torno a una causa noble que restañara sus divisiones, que promovieron o desearon muchos en la época, favoreciendo así un ambiente propicio para el estallido. Entre ellos el ministro del Interior ruso en 1904 quien, en medio de las dificultades internas que enfrentaba el zar Nicolás II, se dice que afirmó "que Rusia necesitaba una pequeña guerra exitosa que apartara la mente de las masas de la política" ${ }^{24}$. Aunque también hay que considerar la existencia de factores coyunturales, de época, como "el asco ante el mundo moderno y los años miserables de la inmundicia y la frivolidad" como los llamó el poeta alemán Stefan George, que hicieron que "muchos intelectuales acogieran la guerra como una posibilidad de purificación social" 25 . También tuvieron su parte nuevos fenómenos que llegaron para quedarse, como el cada vez más trascendente papel de la opinión pública, y por tanto de los medios de comunicación y de prensa, siempre dispuestos a transformar el más insignificante incidente entre los estados en una cuestión de honor nacional, favoreciendo el sentimiento nacionalista. Por ejemplo, cuando a comienzos del siglo XX y a propósito de una crisis con Inglaterra, "de repente la prensa alemana descubrió que Samoa era esencial para el prestigio y la seguridad nacionales"26.

\section{4. "LA GUERra, CUANTO ANTES MEJor"}

Fue el jefe del ejército alemán, Helmuth von Moltke quien, en 1912, pronunció esta sentencia para rebatir al comandante de la armada Alfred von Tirpitz, que prefería postergarla. Y fue en medio de uno de los episodios más controvertidos que antecedieron a la Gran Guerra, por el significado que se le ha atribuido posteriormente: el consejo de guerra del káiser en Potsdam. Los incidentes de la reunión, pero sobre todo las palabras de Moltke el joven, demuestran para MacMillan de forma escalofriante "con cuánta naturalidad aceptaban los presentes que la guerra estaba en camino" 27 . La referencia es pertinente porque el problema que a esta autora le interesa abordar a través de su estudio es “cómo se generan las guerras y cómo podemos preservar la paz"28.

Rechazando la cómoda conclusión que la Gran Guerra fue inevitable, que además considera peligrosa dada la actual situación del mundo, MacMillan ofrece un trabajo

\footnotetext{
23 MacMillan, op. cit., 192.

24 Ibid., 235 y 236.

25 Ibid., 321.

26 Ibid., 105.

27 Ibid., 609.

28 Ibid., 25.
} 
donde lenta, pero contundentemente, demuestra por qué fracasó la paz en 1914 y cómo los estadistas y comandantes de entonces se precipitaron hacia una conflagración que, unos más que otros, consideraron oportuna, deseable incluso, y de todas formas inevitable y, por lo tanto, mejor más temprano que tarde.

$\mathrm{Su}$ obra recorre el camino que condujo a Europa hacia 1914, resaltando los puntos de inflexión que fueron reduciendo las opciones de los futuros combatientes. Sus inquietudes como historiadora no dicen relación con el por qué estalló la conflagración, que es lo que la mayor parte de los estudiosos se ha preguntado, sino con las razones por las cuales no se prolongó la larga paz que, en general, había disfrutado Europa durante casi un siglo. Su foco no son los factores que empujaron a la guerra -o al menos no son apreciados de una manera convencional- sino aquellos que lo hacían en dirección contraria, hacia la paz, aunque a la larga se mostraran ineficaces. Las razones de este fracaso es su gran aporte para hacer algo comprensible lo aparentemente inexplicable, sobre todo cuando el acontecimiento se aborda como si fuera el destino del personaje de una tragedia griega y, por lo tanto, ineludible ${ }^{29}$.

El cambio de interés historiográfico no es menor, pues es a través de la identificación y el análisis de las coyunturas y circunstancias que fueron incrementando la tensión entre los imperios que, finalmente, se llega a comprender el contexto en el que se tomaron las decisiones en 1914. Las sucesivas crisis coloniales que enfrentaron diplomáticamente a los estados, la alianza franco-rusa, la carrera armamentista alemana, la creciente comprensión franco-inglesa, la guerra en los Balcanes y su efecto internacional, son todas razones que aumentaron resentimientos y sospechas, y avivaron recuerdos que terminaron determinando las relaciones entre las potencias. Estas también estuvieron condicionadas por la competencia económica, los nacionalismos étnicos y una opinión pública que presionó a sus líderes por lo que apreciaba como derechos e intereses nacionales.

Entre las tesis de MacMillan, la de que los estadistas de 1914 tomaron sus determinaciones condicionados por las crisis, tensiones y situaciones previas, para no hablar de miedo, es fundamental. Entre otras razones, porque atribuye a los individuos, sus conductas y decisiones un papel esencial, las cuales también están condicionadas por circunstancias que escapan a ellos. De hecho, y adentrándose en un tema sensible como el del azar en la historia, advierte que "no debemos subestimar la intervención en los asuntos humanos de los errores, la desorganización, o sencillamente la falta de sentido de la oportunidad" ${ }^{\prime 30}$. Por ejemplo, la muerte, en realidad, el asesinato del

29 Aprovechando el enfoque de MacMillan, cuánto ganaríamos en comprensión de nuestra historia reciente y del Chile de hoy, si lo aplicáramos al estudio del golpe militar de 1973. También visto por algunos como inevitable y respecto del cual los desequilibrios estructurales o las condiciones generadas por la Guerra Fría - por dar solo dos ejemplos de factores de larga o mediana duración- no han permitido abordar las decisiones y conductas coyunturales de los sujetos y la sociedad que protagonizaron y sufrieron los acontecimientos y sus dramáticas consecuencias. Algunas de las preguntas para comenzar a responder serían: ¿Por qué una sociedad con una institucionalidad política tan valorada entonces fue incapaz de detener lo que antes de que Allende asumiera la presidencia ya se mencionaba como un destino ineludible? ¿Qué impidió que fructificaran todas las medidas destinadas a superar la crisis? ¿Por qué los políticos se conformaron con ser protagonistas de una tragedia cuyas dimensiones jamás tampoco vislumbraron?

30 MacMillan, op. cit., 31. 
prácticamente único sujeto capaz de evitar la guerra en el imperio Austro-Húngaro, el archiduque Francisco Fernando. Además, justo cuando casi todos los líderes, diplomáticos y militares se encontraban de vacaciones y, por lo tanto, impedidos de atender adecuadamente sucesos que, en un comienzo, fueron tomados como un incidente más.

En un contexto europeo marcado por la efervescencia social y nacionalista, todos los estados que terminarían en guerra enfrentaron crisis políticas antes de ella, de modo tal que no es sorprendente que la consideraran un medio para superar antipatías y divisiones. "Aunque perezcamos, habrá estado bien”, sentenció un ministro prusiano el 4 agosto, cuando la lucha se extendía por Europa, reflejando la disposición existente entonces de ir a la guerra ${ }^{31}$.

Erich von Falkenhayn también era parte de un sector social, como casi todos los hombres de Estado y militares de la época, para los que el lenguaje del honor y la vergüenza eran comunes, tanto individual como nacionalmente considerados. Otro factor que los empujó en dirección a la lucha como única vía de resolución de las querellas, pues lo esencial, cualquiera fueran los medios, era preservar el respeto de los demás. Esta actitud convivió con la "triste resignación” respecto "de la perspectiva de una guerra generalizada" 32 , la que, sumada a los temores e inquietudes que se agitaban en Europa antes de 1914, contribuyó también a la glorificación de las virtudes militares y de la guerra misma como instrumentos de supervivencia. No por nada el comandante en jefe británico entre 1895 y 1900 -nos informa MacMillan- consideraba "una mala señal que en aquel momento la sociedad británica tuviera en tan alta estima a los bailarines clásicos y a los cantantes de ópera" ${ }^{33}$. La creciente presencia de la mujer, el descenso de la natalidad -visto como síntoma de escasa virilidady otros factores explican que entonces la guerra pareciera deseable: "una forma digna de luchar contra el destino o una fórmula para revitalizar a la sociedad"34.

Obras como La decadencia de Occidente, de Oswald Spengler, aparecida en 1918, y el darwinismo social reflejaron y favorecieron la aceptación de la lucha como parte esencial de la evolución de la sociedad humana. También los temores y prejuicios de la opinión pública, entre ellos el antisemitismo y el nacionalismo, que facilitaron que el odio y la constatación de las diferencias entre las personas y las sociedades se proyectara contribuyendo a crear un clima propicio para la guerra. Todo sumado al imperialismo, visto como expresión de poderío y vitalidad de una nación, lo que en relación con el nacionalismo aumentó la importancia de los militares como sus defensores privilegiados. Sus grandes victorias militares, que eran ponderadas por los sistemas educacionales sin tener idea "que estaban ayudando a preparar psicológicamente a toda una generación para la Gran Guerra", también fue un factor ${ }^{35}$.

Por lo tanto, afirma MacMillan, "a nadie sorprendió que durante la crisis de preguerra y en el mismo año de 1914, los que tenían la capacidad de decidir optasen

\footnotetext{
31 Las palabras de Erich von Falkenhayn en MacMillan, op. cit., 318.

32 Ibid., 324.

33 Ibid., 329.

34 Ibid., 332.

35 Ibid., 348.
} 
generalmente por la lucha"36. La paz se había vuelto "odiosa y decadente" y los altos mandos de las fuerzas armadas estaban bien dispuestos para la contienda, como MacMillan y los autores citados a lo largo de este ensayo lo demuestran. En una época, además, en que se consideraba que la menor demora en tomar decisiones -es decir en atacar- constituía un peligro; y donde las alianzas ataban a unos y otros en caso de que alguno se viera agredido. "No más miedo, no más cobardía, no más plegarnos a la voluntad alemana; la idea de la guerra es aceptada”, escribió en 1914 el que sería embajador de Francia en Rusia, Maurice Paléologue ${ }^{37}$. Cuando el enfrentamiento se apreció inevitable y el concepto de guerra preventiva prevaleció, todos olvidaron la sentencia de Otto von Bismarck: "La guerra preventiva es como suicidarse por miedo a la muerte" 38 .

Margaret MacMillan, concluye que ante lo ocurrido a partir de 1914, no se sabe si culpar a quienes llevaron a Europa a la guerra por su falta de imaginación para ver cuán destructivo sería el conflicto, o de falta de valor para enfrentarse a quienes decían que no quedaba otra opción que ir a la guerra. Para ella "siempre hay otras opciones".

Como nos demuestran todos los citados en este ensayo, la objetividad del historiador no existe como asepsia valórica, intelectual o política, sino que como rigor metodológico y honestidad intelectual. Esto incluye hacer presente nuestras motivaciones y propósitos, pero también la forma y materiales con que los alcanzamos. Todo en realidad es parte del indispensable marco teórico que algunos se afanan en buscar allende su investigación cuando en realidad lo tienen al alcance de la mano; claro, siempre y cuando hayan investigado concienzudamente.

\section{COMO EXPERIENCIA}

El reconocido historiador de la guerra, Max Hastings, presenta en su texto los sucesos y principales acciones, incluidos atrocidades y comportamientos edificantes, además de toda una gama de acontecimientos y situaciones propias de los campos de batalla que conforman la Gran Guerra. Responde así a lo que considera sensibilidad del lector del siglo XXI, que busca conocer lo que realmente pasó a los combatientes, "enfoque en el factor humano", lo han llamado alguna vez; se beneficia de la inmensidad de fuentes a disposición de los estudiosos, entre ellas las fotografías tomadas por los soldados y su correspondencia; y, también, aprovecha los efectos de la globalización que ha sacado a sus compatriotas de su ensimismamiento, les han hecho dejar atrás la idea de que la historia la hacen ellos, y a él le han permitido incluir en un libro inglés capítulos sobre los frentes serbio y galiziano, y mostrar las enormes bajas sufridas por los franceses. Contribuye así con conocimiento original sobre acciones inéditas hasta ahora para los lectores de Europa occidental, ni qué decir del resto de Occidente.

\footnotetext{
36 Ibid., 333.

37 Ibid., 473.

38 Ibid., 663.
} 
Al igual que MacMillan y otros, Max Hastings también identifica condiciones y componentes de los imperios y estados que terminarían participando en la conflagración, aunque más sucintamente, pues lo suyo es lo ocurrido en el frente de batalla. Argumentando que el asesinato del archiduque Francisco Fernando de Austria-Hungría no fue la causa de la guerra, ya que el hecho habría sido utilizado para "justificar la liberación de fuerzas que ya estaban en juego" "39, entra a explicar la situación de cada uno de los combatientes y, sobre todo, los síntomas y causas, coyunturales y estructurales, que terminaron llevándolos al conflicto en medio de un ambiente internacional cada vez más tenso. Entre las características comunes a todos, la creciente influencia de las respectivas opiniones públicas, volubles y nacionalistas; la carrera armamentista y los planes de contingencia militar; la amenaza socialista y "la creencia de que poseer extensos territorios -el imperio- constituía una medida fundamental de virilidad y grandeza ${ }^{40}$ ". Pero también, el miedo a ser arrollados por el enemigo en un futuro cercano si no se atacaba cuando se creía, equivocadamente como lo demostraron los hechos, se estaba en condiciones de imponerse de manera más o menos rápida. Actitud estimulada, afirma Hastings, por los respectivos altos mandos militares, los que "deseaban demostrar a su gobierno y al pueblo que sus carísimas fuerzas armadas podían llevar a cabo sus fantasías" ${ }^{41}$. A continuación, ofrece ejemplos incontrovertibles de la incompetencia y engreimiento de los mandos militares de uno y otro bando, entre ellos, el error común a todos de poner una fe exagerada en el poder del coraje humano y el haber subestimado terriblemente a sus contrincantes.

Con adjetivaciones que, junto a los hechos que las explican, ahorran mayores comentarios sobre el papel de los militares, entre ellas, "incompetencia de marca mayor" u otras por el estilo, que avalan la sentencia de Helmut von Molke -el viejo Molkeacerca de la clase de oficial más peligrosa $y$, al parecer, entonces predominante: los que "unían a la estupidez una gran energía" ", Hastings concluye que los complejos planes rivales de movilización y despliegue no fueron la causa del conflicto de 1914; "pero las grandes potencias habrían tenido muchas menos ganas de ir a la guerra si sus jefes militares hubieran reconocido la debilidad fundamental de su doctrina ofensiva", escribe. Para este autor "los generales empujaron a los gobiernos hacia el abismo"43.

Pero la suficiencia no fue solo una prerrogativa de los uniformados y, demostrando que las carencias no son atributo de solo un sector y que hay que estar atentos a ponderar todos los factores, Hastings aborda también la actitud del gobierno inglés en la época, censurando su despreocupación frente a las cuestiones extranjeras, exponiéndola como "reflejo del sumo engreimiento moral que se manifestaba en una condescendencia que ofendía especialmente a los alemanes" 44 .

En un medio como el nuestro, donde los jóvenes investigadores en ocasiones están obsesionados con los antecedentes y el contexto, para no mencionar el "marco

\footnotetext{
39 Hastings, op. cit., 29.

40 Ibid., 31.

41 Ibid., 68.

42 Ibid., 68.

${ }^{43}$ Ibid., 73 y 109.

44 Ibid., 77.
} 
teórico", tanto que no terminan nunca de entrar en su tema, Hastings ofrece un ejemplo muy ilustrativo de efectividad para abordar los elementos que explican cómo los involucrados terminaron participando en la guerra. Entre ellos, la naturaleza de la autocracia militar alemana; el papel central del ejército como elemento unificador del imperio Austro-Húngaro; la falta de autoestima unida a una agresividad nacionalista de los rusos; las querellas nacionalistas y la violencia balcánica; la mínima independencia de la política exterior francesa; las tensiones y divisiones de la sociedad y la política inglesa que aceleraban la decadencia de un imperio que se resistía a su destino; las múltiples rivalidades entre los estados; los miedos y ambiciones de unos y otros; la firmeza de los estados, entonces apreciada una virtud; la falta de reacción de los líderes ante acontecimientos que irremediablemente conducían a la conflagración; y, como las mencionadas, otra serie de variables que, en ocasiones implícitamente, en medio del relato de las alternativas del conflicto en 1914, permiten comprender lo aparentemente inexplicable por el horror que comenzaría a vivirse que, como es obvio, las masas ignoraban cuando se manifestaban entusiastamente en las calles a favor de sus agresivos y determinados gobiernos.

Expresión de que, sin embargo, la sociedad percibía que algo de lo que vendría representaba un peligro, es que a fines de julio de 1914, mientras los acontecimientos se desencadenaban en el sentido que conocemos, "por toda Europa -afirma Hastings aguda y efectivamente- los temores de que estallase la tormenta dieron lugar a decenas de miles de bodas apresuradas" ${ }^{45}$.

Mientras las parejas se comprometían ante una eventualidad trágica, otros, líderes como el entonces ministro británico Winston Churchill, apreciaban también la guerra como inevitable, sin por ello mostrar reservas. Así queda en evidencia en una carta a su esposa del 28 de julio, en la que le confiesa: "todo tiende a la catástrofe y el hundimiento. Estoy interesado, preparado y contento" $"$.

El testimonio de Churchill es muy decidor, pues refuerza también una de las tesis de Hastings: que los líderes de las grandes potencias permitieron y luego continuaron la guerra totalmente conscientes de sus actos. Discute así, al aludirlo por el título de su obra, el planteamiento de otro destacado historiador, Christopher Clark quien, en su obra Sonámbulos. Cómo Europa fue a la guerra en $1914^{47}$, sostiene también que la guerra pudo evitarse, pero que los estadistas, gobernantes y protagonistas de ella, al parecer, no tuvieron clara conciencia de sus actos y, menos todavía, de lo que vendría.

El problema del papel de los individuos en la historia, lejos de agotarse, asume cada vez más protagonismo en la historiografía. Así lo demuestran infinidad de obras, pero nos bastará una relacionada con 1914 para señalar que la experiencia vivida entonces se repetiría poco más de una década después, ahora como preámbulo de la crisis económica de 1929, que a su vez explica el ascenso de Hitler, del Nazismo y lo que vendría. Entonces, y como lo explica el original y apasionante libro de

45 Ibid., 106.

46 Ibid., 111.

47 Christopher Clark, Sonámbulos. Cómo Europa fue a la guerra en 1914, Madrid, Galaxia Gutenberg, 2014 (edición original en inglés: Reino Unido, 2012). 
Liaquat Ahamed, Los señores de las finanzas. Los cuatro hombres que arruinaron al mundo, los líderes, esta vez de los bancos centrales de las potencias económicas, tampoco fueron capaces de alterar el curso de los acontecimientos y cambiar las creencias más arraigadas, como el patrón oro y la noción de que el mercado regulaba todo y era innecesaria la intervención del Estado, precipitando así al mundo hacia una crisis de funestas y dramáticas consecuencias ${ }^{48}$.

Pero dar conocer la experiencia humana es uno de los objetivos esenciales de Hastings, en particular la de hombres comunes y corrientes, muchos jóvenes en la plenitud de la vida que, inesperadamente, pasaron de la calle a la trinchera y se vieron transformados en soldados camino a una muerte casi segura ${ }^{49}$. Como el infante Matija Malesic quien, en agosto de 1914, describió la dureza de la marcha hacia el frente, reflexionó sobre la brutal realidad de la guerra y, sobre todo, añoró su Eslovenia natal, "mi madre y una vida idílica que no supe apreciar en lo que valía" escribió, agregando una frase que tal vez se aplica a toda una generación, e incluso a más de una, "probablemente nunca tendré ocasión de disfrutar de nuevo de ella"

Con testimonios como el del joven esloveno, Hastings inicia el relato de lo ocurrido en los campos de batalla durante 1914. Para nosotros, haciendo una verdadera posta con el libro de MacMillan que, precisamente, aborda cómo Europa y el mundo llegaron al enfrentamiento desatado un agosto, hace cien años.

El despliegue del soberbio espectáculo, el del mundo ardiendo en llamas -como lo califica Hastings- incluye el documentado relato de los combates en los que, a fin de cuentas y del año 1914, ninguno de los bandos tuvo la fuerza para imponer un resultado decisivo, y en el que todos los estados participantes cosecharon madres y viudas apesadumbradas desde el primer momento. Entre otras razones, porque al principio los comandantes manejaban muy pródigamente a sus soldados y... "no se preocupaban por las bajas". Aunque más tarde "se vieron obligados a reconocer que la carne y la sangre eran recursos finitos ${ }^{51}$ ",

Horrores, atrocidades, bestialidades, inmensas bajas y pérdidas, saqueos, incendios y catástrofes son algunas de las palabras que acompañan la relación de las batallas y dan cuenta de la tragedia que fue la Gran Guerra que, como Hastings demuestra, se inició "con semanas de espanto" y prosiguió con una "masacre" 52 .

Todo mientras millones y millones de civiles esperaban, a menudo inútilmente, las noticias del campo de batalla, las que, si llegaban, contenían siempre falsedades; y las poblaciones, unas más rápido que otras, se transformaban "en una ciudad de

48 Liaquat Ahamed, Los señores de las finanzas. Los cuatro hombres que arruinaron al mundo, Barcelona, Deusto Ediciones, 2010 (edición original: Lords of Finance: The Bankers Who Broke the World, New York, Penguin Press, 2009).

49 "From Street to Trench: A World War that Shaped a Region", es el nombre de la exposición que el Imperial War Museum en Londres montó para conmemorar el centenario de la Gran Guerra. Como es la tónica de prácticamente todo lo relacionado con la memoria de este acontecimiento hoy, está basada en objetos que ofrecen la perspectiva del hombre y mujer común.

50 Hastings, op. cit., 193.

51 Ibid., 218.

52 Algunos títulos de sus capítulos reflejan su contenido, por ejemplo, "A la muerte con banderas y trompetas” y “Tannenberg: “'Ay! ¿Son tantos miles los que están allí sangrando!’”. 
mujeres", como Helene Schweida escribió desde Bremen a su novio Wilhelm Kaisen el 18 de agosto de $1914^{53}$. Hastings ofrece el desánimo que los acontecimientos provocaron en cada una de las sociedades combatientes, el que se vio estimulado por la llegada de los heridos. Tanto como para que, como ocurrió en Francia, el alto mando ordenara que, para no perjudicar la moral, la población civil tuviera el mínimo contacto posible con ellos. Medida obviamente impracticable, sobre todo si, como ocurrió, muchos heridos debieron ser llevados a casas particulares pues los hospitales se saturaron con rapidez, o bien languidecían en los andenes de las estaciones de ferrocarril, a la vista del que quisiera verlos, en las mismas camillas en que habían sido traídos desde el frente, pues nadie sabía dónde enviarlos.

Desde el punto de vista de los soldados, superada la fase de iniciación, ocurrió, señala Hastings, un fenómeno característico en la mayoría de los conflictos: "No pasa nada nuevo; todo parecía una repetición de las sensaciones vividas antes", en palabras del teniente austriaco Constantin Schneider. "Un asunto cansino", la guerra, que para los que se quedaron atrás, a fines de 1914, había dejado de parecer interesante o gratificante ${ }^{54}$. Incluso más, "representaba un deber profundamente desagradable, que cada uno soportaba con distintos niveles de estoicismo ${ }^{55}$ ".

El esfuerzo de Hastings por develar la guerra "tal y como fue" para quienes la sufrieron en los campos de batalla y la vivieron en la retaguardia se cumple, a nuestro juicio, plenamente, entre otras razones por su abrumador trabajo con las fuentes. Son ellas las que le permiten sostener el relato de la "tragedia europea" durante el año 1914, etapa en que esta tuvo un carácter único. Todos los elementos desplegados explican las premonitorias palabras del barón ruso Nikolai Wrangel en 1913: “estamos en vísperas de unos acontecimientos cuya naturaleza el mundo no ha conocido desde los tiempos de las invasiones bárbaras. Pronto, todo aquello que forma parte de nuestras vidas parecerá inútil a los ojos del mundo. Está a punto de comenzar un periodo de barbarie que durará décadas" 56 .

Pero son frases de Churchill las que sirven de justificación a Hastings para explicar el contenido de su libro, y a nosotros para resumir el foco de interés de la historiografía reciente sobre la Primera Guerra Mundial y su evolución en tragedia de la humanidad: "Ninguna parte de la Gran Guerra se puede comparar, por su interés, con el principio. La acumulación silenciosa y acompasada de unas fuerzas colosales, la incertidumbre sobre sus movimientos y posiciones, la gran cantidad de hechos desconocidos e incognoscibles hicieron de la primera colisión un drama jamás superado. En la guerra tampoco se dio ningún otro periodo en el que la batalla general se librase a tan gran escala, en el que la carnicería fuese tan rápida o hubiera tanto en juego. Por añadidura, al principio, nuestras capacidades de asombro, horror y entusiasmo aun no habían quedado cauterizadas e insensibilizadas por los años de los hornos en llamas ${ }^{57}$ ".

\footnotetext{
53 Hastings, op. cit., 227.

54 Ibid., 605.

55 Idem.

56 Ibid., 53.

${ }^{57}$ Ibid., 17.
} 
